\title{
Reference Curriculum for IoT Applied to Anything: A Proposal
}

\author{
Maisson Lichtenecker, Maria Cristina Carpes Marchesan, Andréia dos Santos Sachete, \\ Fábio Diniz Rossi \\ Federal Institute of Education, Science and Technology Farroupilha, Brazil
}

\begin{abstract}
The focus of this research work is on a reference curriculum that can be used as a basis for undergraduate courses related to the Internet of Things (IoT), and that are applied to a specific area. Numerous studies show methodologies and models for updating curricula. However, such proposals are ossified, since, in the majority, they do not allow flexibility and nor attend to the local characteristics in terms of human resources and local productive arrangement. Our proposal presents a novel IoT curriculum and enable the inclusion of the area to be applied in an easy and significant way to the student, emphasizing interdisciplinarity. The proposed reference curriculum consists of disciplines divided into four major groups: specific group, common group, applied group, and grouping group. In this way, basic disciplines can be complemented with the application area through project disciplines and final works. Besides, disciplines common to all courses reinforce equally important transversal aspects. This proposal for a reference curriculum allows higher education institutions to adapt to a new technology that tends to become dominant in a flexible way, also allowing the provision of a course strongly linked to local or regional potentialities.
\end{abstract}

\section{Introduction}

Humanity has been characterized throughout history by the creation and perfection of technologies to optimize the efforts of man and to make possible feats considered impossible in previous times. To illustrate this situation, we can cite as an example of the evolution of writing that, from the time of its creation, has propelled changes that remain alive to the present day. Today, significant advances in various social spheres are mainly due to information and communication technologies that change the dynamics of the functioning of societies broadly [1].

The rapid evolution of the new technologies brings complex challenges to education and their professionals. The timely and uninterrupted transformations in the conceptions of science show the constant need for continuous training through the most diverse available means and resources. From the perspective of the so-called digital age, it becomes increasingly essential to be aware that we are in a connected world in which information flows very quickly [2].

Therefore, the courses of the computing area, especially, must be connected with such changes [3]. And it has historically occurred, from courses offering closer to electrical engineering, business-oriented training such as information systems courses, and currently, fragmented and specialized courses in specific areas (such as courses for computer networks, information security, artificial intelligence, and so on) [4]. Among several trends in technology, one that comes to attention is the Internet of Things (IoT) [5].

IoT describes a scenario in which several things are connected and communicating. This technological innovation aims to connect the items we use daily to the internet network, making the physical world closer and closer to digital. Mostly, three components need to be combined for an application to function within the IoT concept: (i) devices, (ii) network, and (iii) control system. Devices consist of everything we already know, such as refrigerators, cars, lamps, watches, coffee makers, television, and others. In these devices, they must be equipped with specific items to provide communication to the other elements. These items can be silicon chips, internet connection, sensors, antennas, among others. The network is the communication channel, and we are already habituated with it, because they are technologies such as Wi-Fi, Bluetooth, and mobile data. The control system is necessary for all data captured from the devices through the network to be processed, so they are sent to a system that controls each aspect and makes new connections.

However, the challenge of working with IoT is not restricted to the computational environment. In addition to the knowledge required to build an IoT ecosystem, knowledge of the application target is also required. For example, one initiative that is emerging is the use of the IoT concept for Smart Cities, where they are equipped with integrated networks to ensure the city's functioning in general as mobility, surveillance, and even the control of public transport [6]. Another example is the application of IoT in small stores or markets, where you can instantly inform when a product is sold, and with a sensor, updates the stock of the merchandise. Car mobility and tracing, where IoT shows the location of the vehicle and the time it is parked. In health care, several systems can 
be developed to improve drug delivery, to monitor patients' physical status and vital signs. In the agricultural sector, IoT technologies can also be used, and there are currently sensors systems that send notifications regarding the crop state, the weather and soil conditions, and even pest control. Also, we can use the concept to create unique entertainment experiences, with several objects connected in providing new augmented reality immersions. Based on the above, we propose a general curriculum for IoT courses.

We start by surveying the most prominent literature in the area, and then we present the methodology used for defining the curriculum. Besides, our proposal highlights the knowledge, skills, and abilities required for any IoT-based curriculum. Then, we present a case study that applies our proposed curriculum on an agricultural scenario. After, we present a qualitative evaluation based on several professors' opinions. Finally, we discuss the benefits of this proposal.

\section{Related Work}

There is no reference curriculum for IoT courses, which at the same time offers all the basic disciplines necessary for the complete technical formation, and can be applied in any area, be it agriculture, health, smart cities, and so on. This interdisciplinarity is a challenge that has been discussed in many works. Also, curriculum adaptations can be detrimental to both student and lecturer.

Mawhinney et al. [7] explain that the curriculum of technology courses, especially computing, must always accompany the development of industrial technologies. This makes sense when it comes to the employability of graduates. However, the university must also be a place of criticality, and the technologies taught must also be those that can, in the future, transform and drive the industry. Therefore, there must be a balance between what to teach, what skills are needed for the future professional, and which technologies to master.

Olagunju and Khan [8] state that traditional curricula cannot adapt to rapid changes in IoT technology and the need for new skills on the part of students. The challenge for universities is to adapt to modern times and to absorb new demands and focus on continuous learning dynamically. To stay relevant in the marketplace, professionals will have to sharpen their knowledge more often. Punctual courses of rapid duration will dictate the teaching of the future professional.

De Haan [9] present a workshop initiative within a computer science course that uses Arduino and sensoractuator kits to develop concepts and small IoT solutions. However, the course is not focused exclusively on IoT. It consists of a strategy that enables curricular adjustment aimed at the insertion of current topics (such as IoT). Perhaps this is the easiest way to incorporate IoT into more traditional computer science courses through optional or elective disciplines in which the student can enroll. The major limitation of this model is that the student, when entering this subject must have acquired a series of previous skills in other core subjects so that this subject is well used.

Guerra and Perez [10] feature a curriculum of a computer science course that offers a bias towards IoT, guided by a university partner company. As a result, students can graduate prepared to work with the specific devices of this manufacturer. Although it is a business-university partnership that works in terms of student employability, the course is neither generic nor flexible enough to allow students to proficiency in technologies from other manufacturers.

Burd et al. [11] discuss the difficulty of lecturers specializing in meeting the demands of IoT ecosystems. Much more than technical training, the lecturer from this new context must have a holistic view of all components that integrate into the environment and know the entire chain of artifacts that must be interconnected. It is not an easy task when the course curriculum in which the lecturer acts is ossified. Curricula should be flexible enough also to enable the teacher to perform adequately.

We can see that most attempts to teach IoT on a curricular basis are curriculum adaptations due to flexibility mechanisms. We are proposing otherwise. We suggest an IoT curriculum, with flexibility for other areas.

\section{Curriculum construction method}

Based on the previous and linked to the need for technology courses, and specifically those for computing, to keep up with the labor market and its technologies, the construction of the proposed curriculum began. After, in designing the Analysis Project of the pedagogical and curricular proposal, we aimed to make a diagnosis of the educational proposals and curricula of Brazilian computer science courses, expressed both in written documents and in the way they are implemented in the institutions' daily life. Therefore, it was necessary to build a methodology, including procedures and criteria.

Table 1. ACM Curricula guidelines

\begin{tabular}{|l|c|c|}
\hline \multicolumn{1}{|c|}{ Knowledge Areas } & ACM & Proposal \\
\hline Algorithms and Complexity & $\mathrm{X}$ & $\mathrm{X}$ \\
\hline Architecture and Organization & $\mathrm{X}$ & $\mathrm{X}$ \\
\hline Computational Science & $\mathrm{X}$ & \\
\hline Discrete Structures & $\mathrm{X}$ & \\
\hline Graphics and Visualization & $\mathrm{X}$ & $\mathrm{X}$ \\
\hline Human-Computer Interaction & $\mathrm{X}$ & \\
\hline Information Security & $\mathrm{X}$ & \\
\hline Intelligent Systems & $\mathrm{X}$ & $\mathrm{X}$ \\
\hline Information Management & $\mathrm{X}$ & $\mathrm{X}$ \\
\hline Networking & $\mathrm{X}$ & $\mathrm{X}$ \\
\hline
\end{tabular}




\begin{tabular}{|l|c|c|}
\hline Operating Systems & X & X \\
\hline Platform-Based Development & X & X \\
\hline Parallel and Distributed Systems & X & \\
\hline Programming Languages & X & \\
\hline Software Development & X & \\
\hline Systems Fundamentals & X & \\
\hline Software Engineering & X & X \\
\hline Professional Practice & X & \\
\hline
\end{tabular}

In this process of construction, conceptions and assumptions were expanded, leading to the establishment of a larger objective that would be the development of a methodology that would subsidize both the analysis and evaluation of pedagogicalcurricular proposals, as well as the elaboration of the new project. The construction of the method was a collaborative and dynamic process since it was not based on any closed model. The work was developed in the following steps: (i) Sample definition and collection of pedagogical-curricular proposal documents. (ii) Elaboration of conceptions of educational proposals-curriculum for higher education in computing. (iii) Analysis of the pedagogical projects. (iv) Discussion of the results, preparation of the final report and roadmap of indicators and criteria for the elaboration of the educational proposal in applied IoT.

Professors formed the working group for the creation of this proposal in the area of computing, engineering, and education. This mix of professionals strives for interdisciplinarity since the nature of the curriculum, trying to impress this feature on the course, and on the future egress: the ability to work with multidisciplinary teams. Based on these curricula, the working group produced documents addressing (1) pedagogical proposal concepts/computer curriculum, (2) suggestions for criteria for review and evaluation of documents submitted by universities, and (3) methodology and criteria for analysis of the implementation of the proposals.

The working group considered the curriculum guidelines presented by ACM. As shown in the 2013 Curriculum Guidelines for Undergraduate Degree Programs in Computer Science, our proposal should be multidisciplinary, not too long in time but allowing for a reliable, up-to-date background that meets institutional needs (to address institutional needs, we will present after a review of Brazilian computer science courses that comply with legislation regarding Brazilian curriculum guidelines).

Table 2 shows the result of the working group discussion on the ACM curriculum proposal, where some of the knowledge needed by the computer science professional was prioritized, with a particular focus on the skills required for a professional who will develop IoT solutions.

For analysis, the curricula of the top computer science courses of the ten best Brazilian universities ranked by the QS World University Rankings (USP,
Unicamp, UFMG, UFRJ, UFRGS, PUC-Rio, UFPE, UFSC, PUCRS, UNESP) - were chosen. This phase culminated in the discussion of the documents produced by the working group.

Considering the provided material, some criteria were listed as necessary, namely: There is a need for a flexible and up-to-date curriculum to allow student fluency in any technology involving IoT processes and products. Then, the aim was to arrive at indicators and criteria that constituted instruments of dialogue with any proposal or project and the norms coming from the Ministry of Education.

Table 2 summarized all the work done by the working group and served as the basis for the creation of the new IoT curriculum proposal, which took into consideration essential disciplines pointed out by the working group. However, as the project is a leaner curriculum, some subjects can be worked out in a transdisciplinary manner. More specific ones, such as Sensors, are added.

After that, it was possible to share the acquired experience and to discuss the ideas that emerged from the analysis performed in the previous step, deepening the discussion on the criteria indicators. For the analysis and evaluation of proposals and computation projects previously defined. These procedures allowed to realign the interpretations attributed to the researched universe, besides ratifying the guiding axis built collectively by the workgroup. Thus, it was possible to draw some conclusions about the proposal landscape, to define the working methodology of the next phase, and to elaborate the evaluation script of the implementation of the new proposal.

\section{Proposed Curriculum}

In today's world, there is a need for higher education institutions to reformulate their undergraduate policies in order to overcome current practices stemming from the rigidity of curricula, in courses structured more in the corporate view of the professions than in the perspectives of attention to the context scientific-historical aspects of the areas of knowledge, of meeting the current demands and of inducing new requests more appropriate to society [12].

For these issues to be met, structural changes are necessary for the academic context so that new options for courses and curricula are tried, as well as other educational and pedagogical alternatives to be

implemented. A new course proposal should be in tune with a new worldview, expressed in the new paradigms of society and education, guaranteeing the global and critical formation for those involved in the process, as a way to enable them to exercise citizenship, as well as subjects of the transformation of reality, with answers to the significant contemporary problems [13]. 
Table 2. Computer science core subjects comparison

\begin{tabular}{|c|c|c|c|c|c|c|c|c|c|c|}
\hline & USP & Unicamp & UFMG & UFRJ & UFRGS & PUC-Rio & UFPE & UFSC & PUCRS & UNESP \\
\hline Algorithm & $\mathrm{X}$ & $\mathrm{X}$ & $\mathrm{X}$ & $\mathrm{X}$ & $\mathrm{X}$ & $\mathrm{X}$ & $\mathrm{X}$ & $\mathrm{X}$ & $\mathrm{X}$ & $\mathrm{X}$ \\
\hline Algebra & $\mathrm{X}$ & $\mathrm{X}$ & $\mathrm{X}$ & $\mathrm{X}$ & $\mathrm{X}$ & $\mathrm{X}$ & $\mathrm{X}$ & $\mathrm{X}$ & $\mathrm{X}$ & $\mathrm{X}$ \\
\hline Geometry & $\mathrm{X}$ & $\mathrm{X}$ & $\mathrm{X}$ & $\mathrm{X}$ & $\mathrm{X}$ & $\mathrm{X}$ & $\mathrm{X}$ & $\mathrm{X}$ & $\mathrm{X}$ & $\bar{X}$ \\
\hline Calculus & $\mathrm{X}$ & $\mathrm{X}$ & $\mathrm{X}$ & $\mathrm{X}$ & $\mathrm{X}$ & $\mathrm{X}$ & $\mathrm{X}$ & $\mathrm{X}$ & $\mathrm{X}$ & $\mathrm{X}$ \\
\hline Data Structure & $\mathrm{X}$ & $\mathrm{X}$ & $\mathrm{X}$ & $\mathrm{X}$ & $\mathrm{X}$ & $\mathrm{X}$ & & $\mathrm{X}$ & $\mathrm{X}$ & $\mathrm{X}$ \\
\hline Computer Architecture & $\bar{X}$ & $\mathrm{X}$ & $\mathrm{X}$ & $\mathrm{X}$ & $\mathrm{X}$ & $\bar{X}$ & & $\mathrm{X}$ & $\mathrm{X}$ & $\mathrm{X}$ \\
\hline Computer Organization & & & $\mathrm{X}$ & $\mathrm{X}$ & $\mathrm{X}$ & & & $\mathrm{X}$ & $\mathrm{X}$ & $\mathrm{X}$ \\
\hline Operating Systems & $\mathrm{X}$ & $\mathrm{X}$ & $\mathrm{X}$ & $\mathrm{X}$ & $\mathrm{X}$ & $\mathrm{X}$ & & $\mathrm{X}$ & $\mathrm{X}$ & $\mathrm{X}$ \\
\hline Software Engineering & & $\mathrm{X}$ & $\mathrm{X}$ & & $\mathrm{X}$ & & $\mathrm{X}$ & $\mathrm{X}$ & $\mathrm{X}$ & $\mathrm{X}$ \\
\hline Database & & & $X$ & $X$ & $\mathrm{X}$ & & $\mathrm{X}$ & $\mathrm{X}$ & $\mathrm{X}$ & $\mathrm{X}$ \\
\hline Electronics & & $X$ & & & $\mathrm{X}$ & & & $\mathrm{X}$ & & $\mathrm{X}$ \\
\hline Networking & & $\mathrm{X}$ & $\mathrm{X}$ & $\mathrm{X}$ & $\mathrm{X}$ & $\mathrm{X}$ & $\mathrm{X}$ & $\mathrm{X}$ & $\mathrm{X}$ & $\mathrm{X}$ \\
\hline Circuits & & $\mathrm{X}$ & & & $\mathrm{X}$ & $\mathrm{X}$ & & $\mathrm{X}$ & $\mathrm{X}$ & $\mathrm{X}$ \\
\hline Distributed Systems & & $\mathrm{X}$ & & & $\mathrm{X}$ & & & $\mathrm{X}$ & $\mathrm{X}$ & $\mathrm{X}$ \\
\hline Compilers & & $\mathrm{X}$ & $\mathrm{X}$ & $\mathrm{X}$ & $\mathrm{X}$ & $\mathrm{X}$ & $\mathrm{X}$ & $\mathrm{X}$ & $\mathrm{X}$ & $\mathrm{X}$ \\
\hline Physics & & $\mathrm{X}$ & $\mathrm{X}$ & & $\mathrm{X}$ & & & $\mathrm{X}$ & $\mathrm{X}$ & $\mathrm{X}$ \\
\hline IT Infrastructure & $\mathrm{X}$ & $\mathrm{X}$ & $\mathrm{X}$ & $\mathrm{X}$ & $\mathrm{X}$ & $\mathrm{X}$ & $\mathrm{X}$ & $\mathrm{X}$ & $\mathrm{X}$ & $\mathrm{X}$ \\
\hline
\end{tabular}

Besides the considerations presented, they should contemplate the more general aspects that constitute the frame of this scenario. In all aspects, the scientific and technological innovations and the demands of the world of work acquire relevance in training and professional practice [4].

Based on the above, the proposed course is formatted with a total of 2400 hours, divided into 3 years ( 6 semesters). In this way, such a course can be offered in 20 hours of classes per week, taking into account a 40-week academic year (due to the restrictions of the Brazilian educational legislation).

However, the lesson time quantities can be modified to adjust to other laws. The disciplines offered in the course are divided into 4 major groups: (i) specific group, (ii) common group, (iii) applied group and (iv) grouping group. The specific group presents the technical disciplines of computation and engineering needed for the implementation of the entire IoT infrastructure, from sensors, through communication with edge devices, to final data processing and visualization of information. This group was assembled based on the most important disciplines and in order to maintain coherence with the core of Brazilian computer science courses, based on Tables 1 and 2.

The common group presents the disciplines common to all courses, such as languages and related subjects that are not part of the technical core of the course. The applied group shows the area over which the IoT infrastructure will be used. The grouping group consists of those disciplines that group the diverse knowledge in development of middle and final projects. Together these 4 groups allow the formation of a complete professional for the IoT universe. Figure 1 shows the arrangement of groups and their disciplines.

The specific group of disciplines paves the way in three broad directions that complement each other: (i) electronics, which enable a later knowledge about sensors and their performance in the environment, (ii) programming, starting from algorithms, through data structure , database and software engineering, programming for embedded environments, and ending with backend development for mobile devices, and (iii) the part of computational fundamentals required for the architecture and computers organization and operating systems.

In a transversal way, the curriculum presents IoT infrastructures and networking in order to integrate all the components of the ecosystem. The common group can be filled with those complementary subjects, and in some countries, obligatory. In this scenario, those disciplines that contribute to a broader and more general student education, addressing issues such as citizenship, language, the structuring and legislation, and the professional exercise of future egress in society.

Grouping group is intended to provide students with the opportunity for group problem-solving skills. Also, it allows the integral development of a research project applied to the area, and that enables the student to envision a scientific methodology that assists them in the development of their final work.

The applied group consists of the disciplines in which the IoT ecosystem will be applied. As examples, we can list several areas that currently use (or could use) IoT architectures are in problem-solving processes and support for industry decision-making 4.0, such as health, agriculture, urban mobility, sustainability issues, military applications, and so on.

\section{Case Study}

This section presents an implementation of the previously presented core curriculum with a Common and Applied group proposal that is currently in effect. 
development, technical advice and consulting,
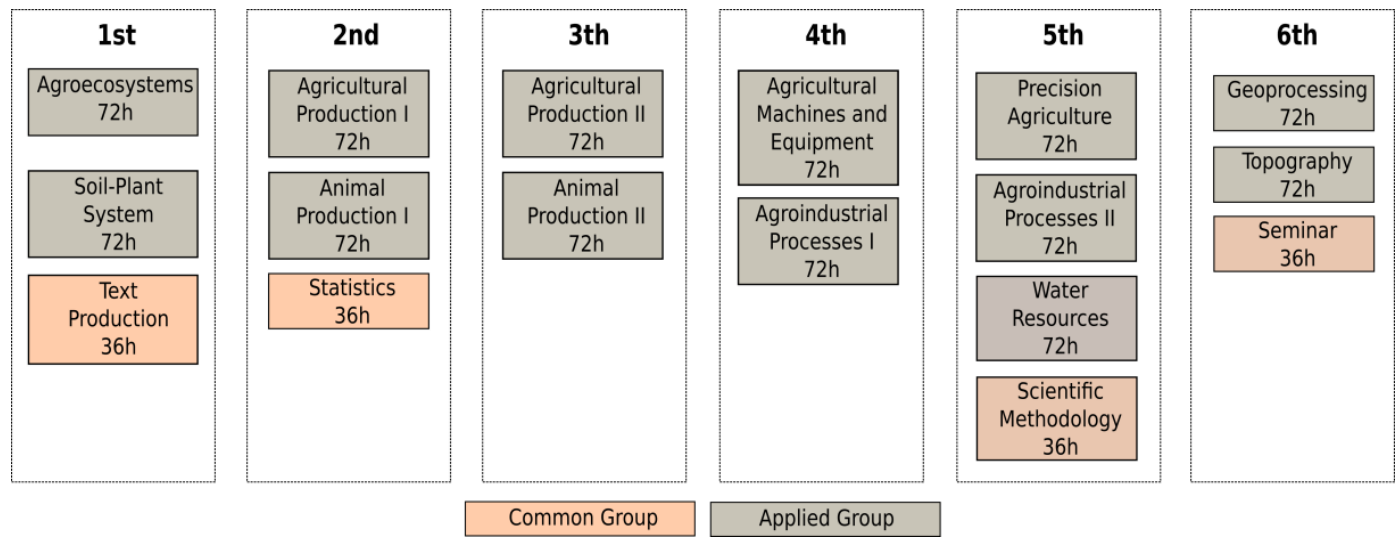

Figure 1. Complementary applied disciplines

The project in Figure 2 consisted of an IoT course applied to the agricultural and animal environment.

The choice of this area occurred due to our local productive arrangement that is purely agricultural and requires the resolution of several open technological problems, which offers several possibilities for both employability and installation of new innovative companies in the region.

In this way, the students will be able to project computational solutions to problems identified in the context of agrarian sciences, apply and relates concepts of software engineering, automation, and agricultural sciences, specify minimum hardware and software requirements for agro-computing systems, develop computerized systems for precision agriculture, manage the process of developing systems in the area of agro-computing, apply national and international industry and market standards in agrocomputing systems, carry out technical and economic feasibility studies in the area, evaluate the socioenvironmental impact of computational solutions in the agrarian environment, apply agro-computing to the rational use of natural resources, manage technical teams in the area.

If we visualize the developmental path presented in Figure 2, we can see that there is an introduction to agricultural systems, a robust conceptualization of farming and animal issues, as well as agro-industrial processes. Finally, disciplines of technologies applied to agro-computing problems are also listed, such as precision agriculture and geoprocessing.

To maintain the course, a minimum infrastructure is indicated as a library, including specific and up-todate collection, laboratory of sensors and embedded computing, geoprocessing, and precision agriculture laboratory, and laboratory of agro-automation (irrigation and agricultural mechanization).

We hope that the graduates of this agro-computing course can work in companies of planning, project companies and organizations in the agricultural sector, institutes and research centers, and institutions, through the training required by current legislation.

\section{Discussion}

An IoT curriculum should address specific skills. Man-Machine interaction is at the heart of the Internet of Things. Therefore, the ability of systems to communicate must also include men and their natural languages such as speech, gestures, and looks. The way the users interact with the system, how they provide inputs, and how they receive the results must be carefully thought.

It is cognitive computing that will give even more intelligence to devices, allowing them to learn from and respond to human interactions, making the user experience more dynamic. In constant learning, cognitive IoT devices will be able to improve themselves and deliver more and more value to the population in a personalized, natural, and predictive way.

Considering this scenario, knowledge related to artificial intelligence, human-machine interface, natural language, speech recognition, among others related to cognitive computing, will be much appreciated. The professionals in this area must have experience with electronic devices and their components such as power source, microcontroller, modem, GPS, sensors, among others. You need to understand how these "small" systems work and how to connect and program them.

Specifically, in the case of sensors, it will be necessary to know simulators that can be used in the development stage. It is because it is often challenging to create a production-like environment, especially considering a scenario where the solution being developed has dozens or even hundreds of sensors. 
In situations like this, it becomes impracticable to reproduce the environment for the development and testing, so that the simulators come into play. In addition to the intelligence that can be embedded into devices through software, IoT systems can also feature other software components, such as backend support and management systems, dashboards, reports, and mobile applications. The development of all these components requires professionals specialized in various areas of software development, be it embedded, enterprise, web, or mobile.

One of the main barriers to popularizing the IoT at the projected level is the lack of open standards that allow integration between solutions developed by different manufacturers. To better understand, these patterns have different purposes and are intended for specific use cases, such as defining how one device will connect with another? How will the system connect to the internet? How will data be transferred to servers? How will servers send messages to each other and more?

To get an idea, just for the wireless connection, professionals in the field will have more than 20 protocol options available [14]. While efforts to unify them not affect, it is essential that the practitioner working in this area understands the application of each.

It is crucial to understand the requirements and needs of the product to define which protocol is best suited for each case. Therefore, one needs to know in detail what each protocol is for and its particularities. Besides, one of the first challenges of IoT systems is being able to process the volume of data produced by connected devices. It is estimated that the number of data generated by the digital economy is doubling every two years.

By 2020, the number of gigabytes generated annually is expected to reach 44 trillion [15]. To overcome this challenge, it will be essential to have the ability to efficiently access, process, and understand data and present condensed information. Cognitive computing will be an excellent ally for companies to extract insights from this immense volume of data, whether structured or unstructured. While technology plays a vital role, practitioners will need to develop models - based on tools and techniques - to define how this data will be collected, updated, and stored and what is the best framework for doing so.

We need to develop data models that allow us to generate information and knowledge with high performance. And to make decisions about the best data model, there's no denying the importance of knowing databases, big data, and analytics to extract business value from that information.

Finally, concerns about the security of IoT devices are significant, even higher than those of a software system. There are rare reports of intrusions to cloudconnected devices, adding to the feeling of insecurity that surrounds the area. Despite being a concern, the security aspect does not seem to be a priority in the development of these products as the technology itself is still a challenge.

Much thought is given to how to ensure user safety in a surveillance system, for example, but the system itself is insecure. This scenario opens space for professionals in this field. It offers opportunities not only for security specialists but also for developers in general because it is a little-explored aspect of IoT and lacking supportive solutions.

All these competencies are represented in this curriculum proposal. Knowledge about humanmachine integration, manipulation of electronic actuator and sensor devices, standardization of data communication, processing of large volumes of data, and safety.

\section{Qualitative Evaluation}

As the curriculum presented is still in the proposal stage, ie, it has not yet been implemented in a real environment, we show a qualitative assessment based on the opinion of several computer science professors and IoT specialists.

To do so, we use an adaptation of the System Usability Scale (SUS) [16], which is generally used to measure software acceptability by users. This survey consists of 10 questions, and the possible answers are formatted as a Likert scale with five options. The range of scale response options range from 1 (strongly disagree) to 5 (strongly agree). The adapted questions are:

1. I think that I would like to use this curriculum.

2. I found the curriculum unnecessarily complex.

3. I thought the curriculum was easy to implement.

4. I think that I would need the support of a technical person to be able to implement this curriculum.

5. I found the various functions in this curriculum were well integrated.

6. I thought there was too much inconsistency in this curriculum.

7. I would imagine that universities would adapt to use this curriculum very quickly.

8. I found the curriculum very cumbersome to use.

9. I felt very confident in implementing the curriculum.

10. I needed to learn a lot of things before I could implement this curriculum. 


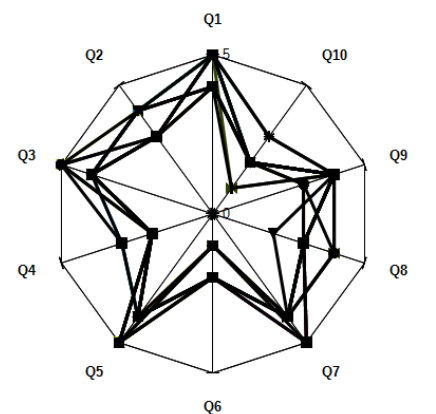

Figure 2. Summary of SUS responses

After collecting the results, the results should be integrated. For odd answers $(1,3,5)$, subtract 1 from the score the user answered. For even answers $(2$ and 4 ), subtract the answer from 5. That is, if the user answered 2, count 3. If the user answered 4, count 1 . After, all weight values must be summed and multiplied by 2.5 . This is the final score, which can range from 0 to 100 .

The average System Usability Score is 68 points. Any value below 68 points demonstrates that there is a limitation on the usability or application of the proposal, and any amount above this average shows that respondents well accept the proposal.

The qualitative research was conducted with 20 teachers from different Brazilian higher education institutions. The answers are summarized in Figure 3. The result of the SUS evaluation was 70 points. This means that the curriculum proposal is well accepted and consistent, with the relative ease of implementation for universities, and shows evidence that educational institutions can adopt this proposal to their demands.

\section{Conclusions}

When the term IoT was coined in the 1990s, we had no idea how important the subject would gain over the years. The interconnection of smart devices capable of controlling, exchanging or sharing information and data, without the need for physical interaction with humans, is already a reality in many sectors and should increasingly impact the world economy.

Remote monitoring of health and fitness through wearable devices, patient-bed sensors, and support for identifying syndromes and epidemics are some examples of how the IoT can benefit patients, hospitals, and operators alike, allowing improvements in communication between all and contributing to preventive and assertive diagnoses. In the industrial sector, many IoT applications can improve processes, reduce excess and costs, create new business models, and speed up operations.

Industrial Internet of Things (IIoT) enables integrated activity monitoring, resulting in an extensive database that assists in automated decision making from machine and equipment integration. Such an advance also requires a more significant concern for information security and data protection. It is essential to be prepared to detect potential cyber attacks that may cause physical damage to an industrial facility or impair plant functionality. In healthcare, care must be even higher, as failures can have irreversible impacts on people's lives.

The more devices connected to a network, the more opportunities for fault exposure and exploitation are possible. Just as the IoT promises to facilitate processes and activities, it also demands a lot of responsibility for protection. Maintaining a consolidated security policy is essential, as well as continuous monitoring of IoT devices and the adoption of damage mitigation measures. And now, companies can also respond to these changing market conditions with agility and flexibility.

IoT professionals have to understand existing and emerging technologies. One of the core competencies that all IoT professionals need to have is a deep and broad knowledge base about these technologies in their technical skills. These skill differences lead to an entirely new industry within the job market.

Relying on the right skills is critical to applying IoT and being able to keep up with developments in the new segment. After all, data is never stagnant, and technological change is constant. Therefore, professionals in the field will need to be aware to keep the company always moving and up to date with the industrial internet.

This work proposes a reference curriculum of an IoT course applied to any area of knowledge, presenting a primary curriculum that offers all the necessary skills for the technical understanding of the environment, and which allows curricular flexibility to suit the most diverse specific contexts.

\section{References}

[1] M. Y. Vardi, Technology for the most effective use of mankind, Commun. ACM 60 (1) (2016) 5-5. doi: $10.1145 / 3020075$.

[2] J. Casap, The speed of learning, in: 2019 ACM SIGUCCS Annual Conference, SIGUCCS '19, ACM, New York, NY, USA, 2019, pp. 2-2. doi:420 10.1145/3347709.3347769.

[3] L. Brown, L. Fox, M. Carney-Morris, B. Lynn Nolen, Training faculty: Teaching goals vs. tech tools - finding a balance, in: 2019 ACM SIGUCCS Annual Conference, SIGUCCS '19, ACM, New York, NY, USA, 2019, pp. 425 236-236. doi:10.1145/3347709.3347823.

[4] M. Guzdial, A. Kay, C. Norris, E. Soloway, Computational thinking should just be good thinking, Commun. ACM 62 (11) (2019) 28-30. doi: $10.1145 / 3363181$. 
[5] J. Gubbi, R. Buyya, S. Marusic, M. Palaniswami Internet of things (iot): A vision, architectural elements, and future directions, Future Gener. Comput. Syst. 29 (7) (2013) 1645-1660. doi:10.1016/j.future.2013.01.010.

[6] S. Singh, N. Singh, Internet of things (iot): Security challenges, business opportunities reference architecture for e-commerce, in: 2015 International Conference on Green Computing and Internet of Things (ICGCIoT), 2015, pp. 1577-1581. doi:10.1109/ICGCIoT.2015.7380718.

[7] C. H. Mawhinney, J. S. Morrell, G. J. Morris, S. R. Monroe, Updating the is curriculum: Faculty perceptions of industry needs, in: Proceedings of the 1999 ACM SIGCPR Conference on Computer Personnel Research, SIGCPR '99, ACM, New York, NY, USA, 1999, pp. 219-221. doi:10.1145/299513.299681.

[8] A. O. Olagunju, F. Khan, Challenges of interdisciplinary iot curriculum, in: Proceedings of the 17th Annual Conference on Information Technology Education, SIGITE '16, ACM, New York, NY, USA, 2016, pp. 110-110. doi: $10.1145 / 2978192.2978200$.

[9] G. de Haan, A hands-on approach to making in the internet of things and creative technology, in: Proceedings of the European Conference on Cognitive Ergonomics, ECCE '16, ACM, New York, NY, USA, 2016, pp. 1:1-1:4. doi:10.1145/2970930.2970932.

[10] J. Guerra Guerra, A. Fermin Perez, Alignment of undergraduate curriculum for learning iot in a computer science faculty, in: Proceedings of the 2017 ACM Conference on Innovation and Technology in Computer Science Education, ITiCSE '17, ACM, New York, NY, USA, 2017, pp. 362-362. doi:10.1145/3059009.3073001.

[11] B. Burd, L. Barker, M. Divitini, J. G. Guerra, F. A. F. Perez, I. Russell, B. Siever, L. Tudor, M. McCarthy, I Pollock, The internet of things in cs education: Updating curricula and exploring pedagogy, in: Proceedings of the 23rd Annual ACM Conference on Innovation and Technology in Computer Science Education, ITiCSE 2018, ACM, New York, NY, USA, 2018, pp. 366-367. doi: $10.1145 / 3197091.3205846$.

[12] K. Tsarava, L. Leifheit, M. Ninaus, M. RománGonzález, M. V. Butz, J. Golle, U. Trautwein, K. Moeller, Cognitive correlates of computational thinking: Evaluation of a blended unplugged/plugged-in course, in: Proceedings of the 14th Workshop in Primary and Secondary Computing Education, WiPSCE'19, ACM, New York, NY, USA, 2019, pp. 24:1-24:9. doi:10.1145/3361721.3361729.

[13] A. Dengel, Computer science replugged: What is the use of virtual reality in computer science education?, in: Proceedings of the 14th Workshop in Primary and Secondary Computing Education, WiPSCE'19, ACM, New York, NY, USA, 2019, pp. 21:1-21:3 doi: $10.1145 / 3361721.3362113$

[14] S. Majdoul, M. N. Srifi, Wireless sensors networks challenges, in: Proceedings of the Mediterranean Symposium on Smart City Application, SCAMS '17, ACM, New York, NY, USA, 2017, pp. 15:1-15:3 doi: $10.1145 / 3175628.3175637$.
[15] C.-W. Tsai, C.-F. Lai, H.-C. Chao, A. V. Vasilakos, Big data analytics: a survey, Journal of Big Data 2 (1) (2015) 21. doi:10.1186/s40537-015-0030-3.

[16] J. R. Lewis, J. Sauro, Item benchmarks for the system usability scale, J. Usability Studies 13 (3) (2018) 158-167. 